\title{
SOLVENT EFFECTS ON THE THERMODYNAMICS OF SOLVATION OF BARIUUM DIPHENYLAMINESULFONATE IN ETHANOL-WATER MIXED SOLVENTS
}

\author{
Esam A. Gomaa ${ }^{*}$, Elsayed M. Abou Elleef ${ }^{2}$, E.T.Helmy ${ }^{1}$ and Sh.M.Defrawy ${ }^{1}$ \\ ${ }^{4}$ Chemistry Department, Faculty of Science, Mansoura University, \\ 35516-Mansoura, EGYPT \\ ${ }^{2}$ Basic Science Department, Delta Higher Institute for Engineering \& Technology, \\ 35681-Dakhlia, Mansoura, EGYPT.
}

\begin{abstract}
Aims: The aim of this study was to determine the thermodynamic functions, Gibbs energy, enthalpy and entropy for the solution processes of barium diphenylaminesulfonate in the mixed solvent (ethanol + water) were calculated from solubility values obtained at temperatures ranging from $293.15 \mathrm{~K}$ to $308.15 \mathrm{~K}$. The respective thermodynamic functions for mixing and solvation processes as well as the activity coefficients for the solute were calculated. The solubility of solutes in mixed solvents depends primarily on the solvation of the solutes or their constituent ions by the components of the solvent mixtures. In this study, the solubility of this barium diphenylaminesulfonate in the mixed solvent (ethanol + water by value percent of ethanol $=0,20,40,60,80$ and 100\% by volume), was determined at different temperature by the solvent evaporation method. The results enable us to estimate the value of thermodynamic solibility product, $K_{o p(t h),}$ of barium diphenylaminesulfonate in the mixed solvent. In addition, Gibbs energy, enthalpy, entropy for the solution processes and free energies of transfer of barium diphenylaminesulfonate units from water to the ethanol solutions were also calculated in order to estimate the contributions solute-solvent interactions related ion association are based on changes in the electrostatic properties of the solvent, solute and ion solvation as well as on the ionic strength of the medium.
\end{abstract}

KEY WORDS: Solubility; thermodynamics; solubility product; mixed solvents; barium diphenylaminesulfonate

Place and Duration of Study:

1. Chemistry Department, Faculty of Science, Mansoura University, Egypt

2. Basic Science Department, Delta Higher Institute of Engineering and Technology, Dakhlia, Mansoura, Egypt between June 2012 and July 2013

\section{RESUMO}

Opropósito deste estudo foi determinar as propriedades termodinâmicas tais com energia livre de Gibbs, entalpia e entropia para o processo de solubilização de difenilaminesulfonato de bário em solvente misto consistindo de etanol-água a várias temperaturas. Foi determinada a constante de solubilidade, Ksp , $e$ foram analisados também fatores tais como interaçôes soluto-solvente, propriedades eletrostáticas, solvatação de tons e a força înnica do meio.

PALAVRAS CHAVE: Solubilidade, termodinâmica, solventes mistos, Ksp, difenilaminesulfonato de bário

VISIT OUR SITE: http:/www.sbjchem.he.com.br 


\section{SOUTHERN BRAZILIAN, JOURNAL OF CHEMISTRY \\ SOUTH. BRAZ. J. CHEM., Vol. 21, No. 21, 2013}

Thermodynamics of Solvatoion of Barium Diphenylaminesulfonate

\section{INTRODUCTION}

The solubility of solutes of all kinds in mixed solvents is of great practical importance, since many industrial process as well as laboratory procedures call for the use of solvent mixtures, or such mixtures are used by default [1]. Most physicochemical properties of ionic solutions are influenced by ionic strength and the solvent's dielectric constant. Indeed, in the context of solution chemistry, solvent polarity, the dielectric constant of the solvent, and the ionic strength of the medium are of great interest as a measure of the solvent's ability to stabilize charges or dipoles. As an example, the dissolution of an ionic salt in a solvent or in a mixed solvent depends on the relative permittivity and the polarity of the solvent as well as on the lattice energy of the solute and the ionic strength of the medium [2-4].

The solvation of dissolved ions determines many of the properties of electrolyte solutions [5-7], including their redox, complexation, and kinetic behavior. Its particular importance to solubilities, the central topic of the international symposium on solubility phenomena, is illustrated by the thermodynamic cycle in Fig. 1. As shown, the (standard) Gibbs energy of solution, $\Delta_{\text {soln }} G^{\circ}$, is seen to be the sum of (the negative of the) lattice energy of the salt, $\Delta_{\text {latt }} G^{\circ}$, and the solvation energies of the ions, $\Delta_{\text {solv }} G^{\circ}$. This cycle makes it clear that the only reason that salts dissolve in solvents is because the very large lattice energies that are lost upon dissolution are compensated by the even larger solvation energies of the ions.

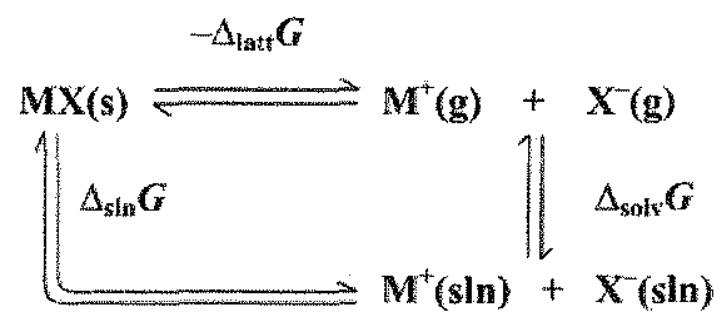

Fig. 1 Born-Haber cycle for dissolution of the salt MX.

Because both $\Delta_{\text {latt }} G^{\circ}$ and $\Delta_{\text {solv }} G^{\circ}$ are very large (negative) quantities, typically of the order of $-1000 \mathrm{~kJ} / \mathrm{mol}$, it follows that relatively small changes in either, for example, arising from minor changes in the nature of the solvent or the salt, can result in dramatic changes in solubility. Given that

$$
\Delta_{\mathrm{sin}} \mathrm{G}^{\circ}=-\operatorname{RT} \ln \mathrm{K}_{\mathrm{sp}}^{0}=2.303 R T p K_{\mathrm{sp}}^{0}
$$


where $R$ and $T$ have their usual meanings and $\mathbf{K}_{\mathrm{sp}}^{\mathbf{0}}$ is the (standard) solubility product of the salt:

In turn, most of the theories that have been used to predict the extend of solubility of an ionic compound in a given solvent or in a mixed solvent and related ion association are based on changes in the electrostatic properties of the solvent, solute and ion solvation as well as on the ionic strength of the medium [8-15].

\section{EXPERIMENTAL}

\subsection{Chemicals and Reagents}

Barium diphenylaminesulfonate and ethanol were purchased from Merck Company with high degree of purity and used without further purification.

\subsection{Preparation of mixed solvent and saturated solutions}

The mixed solvent, (ethanol + water by value percent of ethanol $=0,20,40$, 60,80 and $100 \%$ by volume), were prepared from deionized water and fairly pure ethanol. Then, saturated solutions of barium diphenylaminesulfonate were prepared by dissolving different amounts in closed test tubes containing different (ethanol + water) mixtures. These mixtures were then saturated with nitrogen gas an inert atmosphere. The tubes were placed in a shaking thermostat (Model Gel) for a period of four days till equilibrium reached. The solubility, $\mathrm{S}$ (g.mole/Kg.solvent), of barium diphenylaminesulfonate in the mixed solvent at different temperature was determined gravimetrically by the solvent evaporating method. All the solubility experiments were repeated at least three times and the results were averaged.

\section{RESULTS AND DISCUSSION}

For an ionic compound, with the formula $\mathrm{BA}_{2}$, we may consider the following equilibrium in its saturated solution at a given constant temperature.

$$
\mathrm{BA}_{2}(\mathrm{~s}) \quad \leftrightarrow \quad \mathbf{B}^{2+}{ }_{(\mathrm{aq})}+2 \mathrm{~A}_{\text {(aq) }}^{-}, \quad \mathrm{K}_{\mathrm{sp}(\mathrm{th})}=\mathrm{a}_{+} \cdot \mathrm{a}_{-}{ }^{2}
$$

Where $\mathrm{K}_{\mathrm{sp}(\mathrm{th})}$ denotes the thermodynamic solubility product constant and $\mathrm{a}_{+}$ and a. refer to activity of $\mathrm{B}^{2+}$ and $\mathrm{A}^{-}$in the solution, respectively. If the 
solubility of $\mathrm{BA}_{2}$ is very low, it may replace the activity of each ion by its concentration, $\mathrm{S}_{\mathrm{o}}$

$$
\mathrm{K}_{\mathrm{sp}(\mathrm{th})}=4 \mathrm{~S}_{\mathbf{0}}^{\hat{\mathrm{s}}}
$$

Where $\mathrm{S}_{\mathrm{o}}$ represents the molarity of $\mathrm{BA}_{2}$ in the very dilute solution. The electrostatic interaction becomes very small and the ion association phenomenon may be negligible (the activity coefficient $\gamma_{ \pm} \sim 1$, [16-21].

At low concentration, the activity coefficient may be determined by using the Debye-Huckel limiting law:

$$
\log \gamma_{ \pm}=-Z_{+} Z_{-} A \sqrt{\mathbf{I}} \text { applicable for } \mathbf{I}<\mathbf{1 0}^{-2} \mathbf{M}
$$

Where $Z_{+}$and $Z_{-}$are the charges of ions in solutions, $A=\mathbf{1 . 8 2 3} \times \mathbf{1 0}(\varepsilon . T)$ the ionic strength, $\mathrm{I}$, defined as, $I=\frac{1}{2} \sum_{i} m_{i} Z_{i}^{\mathrm{z}}\left(\mathrm{z}_{\mathrm{i}}\right.$ is the charge on ion $\mathrm{i}$, and $\mathrm{m}_{\mathrm{i}}$ is the molality of ion i) and the ionic strength, I emphasizes the charges of ions because the charge numbers occur as their squares. The values of dielectric constant $(\varepsilon)$ for ethanol-water mixtures were taken from previous publications [22].

On the other hand, it can be considered that at high concentration, the solubility product constant $\left(\mathrm{K}_{\mathrm{sp}}\right)$ is given by:

$$
K_{\text {sp }}=4 S^{3} \gamma_{ \pm}{ }^{3}
$$

where $\mathrm{S}$ is the molal solubility of $\mathrm{BA}_{2}$ and $\gamma_{ \pm}$is the mean molal activity coefficient. There are several theoretically-based expressions that can be used to estimate single ion activity coefficients [15]. At relatively high concentration, the electrostatic interaction becomes very large [23-26]. The activity coefficient may be determined using the extend Debye-Hückel law:

$$
\log \gamma_{ \pm}=-\frac{Z_{+} Z A \sqrt{I}}{I+B^{\circ} \sqrt{I}} \quad \text { for } \quad I<10^{-1} M
$$

Where $\mathbf{B}=\mathbf{5 0 . 2 9}(\varepsilon . \mathbf{T})^{-1 / 2}$, and $\mathrm{r}^{\circ}$ is the solvated radius.

At high concentrations, activity coefficients of electrolyte solutions can be determined by using the Davies equation [27] which is an empirical extension of Debye-Hückel theory. The final form of the equation gives the mean molal activity coefficient, $\gamma_{ \pm}$, of an electrolyte which dissociates into

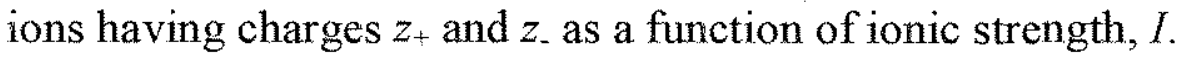




$$
\log \gamma_{ \pm}=-Z_{+} Z_{-} \mathbf{A}\left(\frac{\sqrt{\mathbf{I}}}{\mathbf{I}+\sqrt{\mathbf{I}}}-0.3 \mathbf{I}\right)
$$

The second term, $0.3 I$, goes to zero as the ionic strength goes to zero, so the equation reduces to the Debye-Hückel equation at low concentration. However, as concentration increases, the second term becomes increasingly important, so the Davies equation can be used for solutions too concentrated to allow the use of the Debye-Hückel equation.

The molal solubility , S (g.mole/ $\mathrm{Kg}$.solvent), of barium diphenylaminesulfonate in the mixed solvent at different temperature was determined gravimetrically by the solvent evaporating method. The solubility values and activity coefficients are cited in Tabie $i_{p}$.

The solubility of saturated solution of barium diphenylaminesulfonate in mixed solvents found to decrease with the increase the mole fraction of $\mathrm{EtOH}$ in the mixed solvent and increase with increase temperature depends primarily on the solvation of the solutes or their constituent ions by the components of the solvent mixtures. The saturated solution of diphenyl amine barium salt in the mixed solvent is perfectly non-ideal. The nonideality is partly due to the mean activity coefficient of ions in the solution and partly due to the ion association phenomenon.

The solubility product was calculated by the use of equation (7).

$$
\mathrm{pK}_{\mathrm{sp}}=-4\left(\log \mathrm{S}^{3}+\log \gamma_{ \pm}{ }^{3}\right) \ldots \ldots \ldots \ldots \ldots \ldots . . . . .(7)
$$

The solubility product $\left(\mathrm{pK}_{\mathrm{sp}}\right)$ data are given in Table (2), the Gibbs free energies of solvation and the transfer Gibbs free energies from water to mixed solvents were calculated by using equations (8) and (9) [28-32]. Their values are tabulated also in Table (2) and Table (3).

$$
\begin{aligned}
& \Delta G^{0}=2.303 R T p K_{s p} \\
& \Delta G_{t}=\Delta G_{s}-\Delta G_{w}
\end{aligned}
$$

Where (s), (w) denote solvent and water, respectively.

The enthalpy change of solvation $(\Delta \mathrm{H})_{\mathrm{s}}$ were calculated From the plots of $\log \mathrm{K}_{\text {sp. }}$ versus $\frac{1}{T}$ as shown in Figs. 1, where the slope equals $-\Delta H / 2.303 R$ using van 't Hoff equation [33]:- 
36

$$
\log K=-\frac{\Delta H^{j}}{2.303 R}\left(\frac{1}{T}\right)+\operatorname{cons} \tan t
$$

From equation (18) \& (20) the values of $(\Delta \mathrm{G})_{\mathrm{S}}$ and $(\Delta \mathrm{H})_{\mathrm{S}}$ can be used to calculate the values of $\mathrm{T} \Delta \mathrm{S}$ at different temperatures according to GibbsHelmholtz equation (12) [32] and all the results are reported in Table (3).

$$
(\Delta \mathbf{G})_{\mathrm{s}}=(\Delta \mathbf{H})_{\mathrm{s}}-(\mathbf{T} \Delta \mathbf{S})_{\mathrm{s}}
$$

The magnitude of $\Delta G_{\mathrm{t} \text { (solute, } \mathrm{w} \rightarrow \mathrm{w}+\mathrm{s} \text { ) }}$ as shown in Figs. 2 is a measure of the overall change in the solvation (energy) of an ion upon its transfer from water to an organic-aqueous mixture. Such quantities are usually "well behaved" in the sense that they vary smoothly as a function of solvent composition, even though they may show great diversity. It was concluded that the Gibbs free energies of transfer increase in negativity by increasing the mole fraction of EtOH in the mixed $\mathrm{EtOH}-\mathrm{H}_{2} \mathrm{O}$ solvents indicating the decrease in spontaneous nature of barium diphenylaminesulfonate solubilization. This is due to more solvation behaviour in water than that of the mixed solvents where the Gibbs free energy values provide information on whether the process conditions favor or disfavor barium diphenylaminesulfonate solubilization in the aqueous carrier solution. Positive Gibbs free energy values indicate disfavourable conditions.

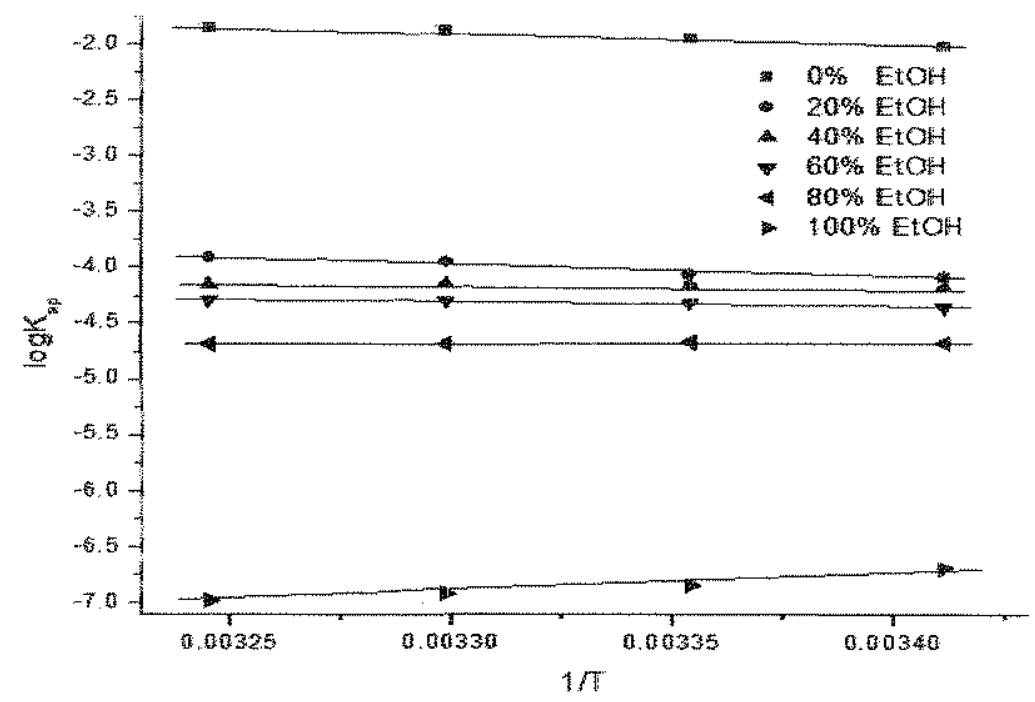

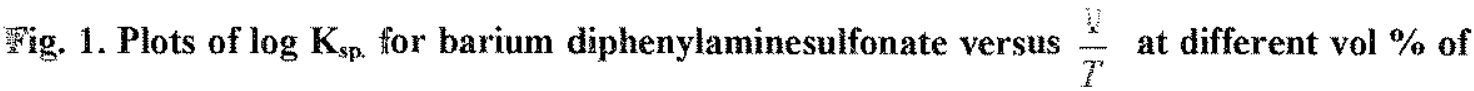
EtOH. 
SOUTHERN BRAZILIAN, JOURNAL OF CHEMISTRY

SOUTH. BRAZ. J. CHEM. , Vol. 21, No. 21, 2013

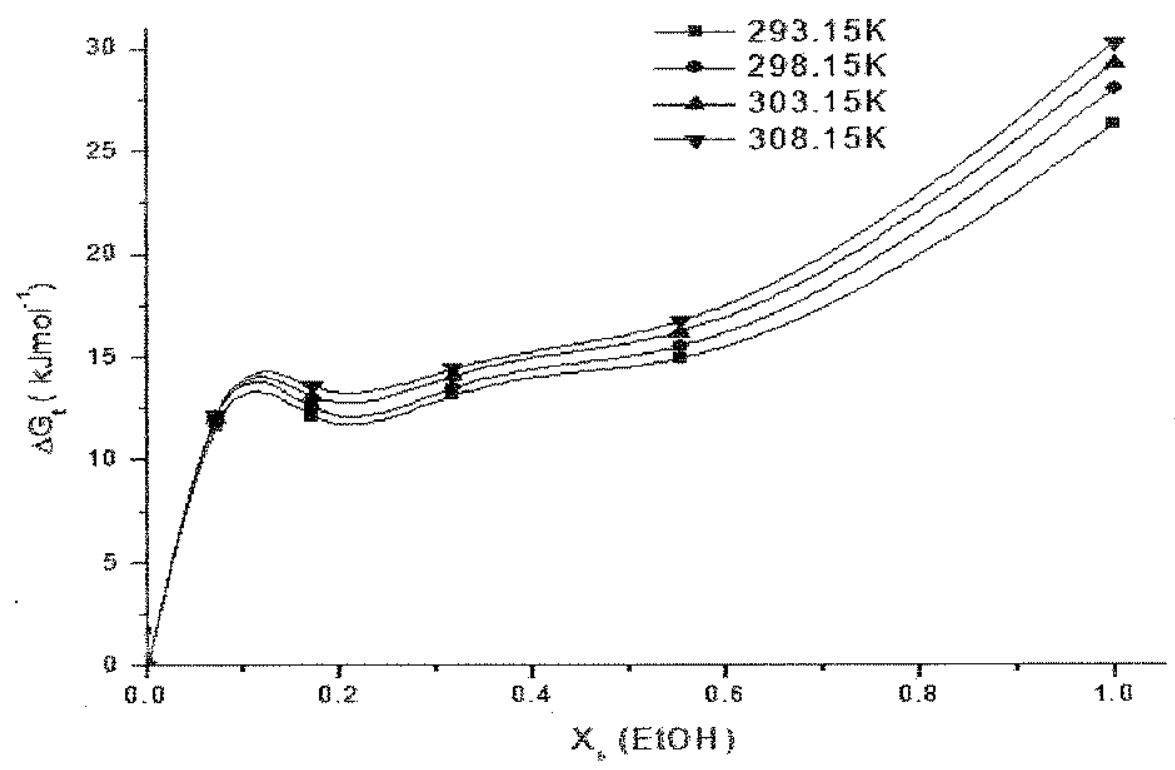

Fig. 2. Gibbs free energies of transfer ( $\Delta G t)$ for barium diphenylaminesulfonate versus the mole fraction $\left(\mathrm{X}_{\mathrm{s}}\right)$ of EtOH at different temperature.

Table 1. Solubilities and molal activity coefficients for barium diphenylaminesulfonate in mixed EtOH-H2O solvents at different temperature.

\begin{tabular}{|c|c|c|c|c|c|c|c|c|c|}
\hline EtOH\% & $X_{s}$ & \multicolumn{5}{|c|}{ S,g. mol/kg solvent } & \multicolumn{5}{c|}{ log $\gamma_{ \pm}$} \\
\hline By vol. & EtOH & $293.15 \mathrm{~K}$ & $298.15 \mathrm{~K}$ & $303.15 \mathrm{~K}$ & $308.15 \mathrm{~K}$ & $293.15 \mathrm{~K}$ & $298.15 \mathrm{~K}$ & $303.15 \mathrm{~K}$ & $308.15 \mathrm{~K}$ \\
\hline 0 & 0 & 0.2416 & 0.2548 & 0.2682 & 0.2753 & 0.5513 & 0.5518 & 0.5516 & 0.5508 \\
\hline 20 & 0.0717 & 0.0468 & 0.0485 & 0.0538 & 0.0569 & 0.5792 & 0.5729 & 0.5605 & 0.5510 \\
\hline 40 & 0.1708 & 0.046 & 0.0479 & 0.0489 & 0.049 & 0.5515 & 0.5428 & 0.5369 & 0.5316 \\
\hline 60 & 0.3166 & 0.0451 & 0.0468 & 0.0476 & 0.0481 & 0.4924 & 0.4902 & 0.4868 & 0.4844 \\
\hline 80 & 0.5527 & 0.0446 & 0.0464 & 0.0468 & 0.0474 & 0.3878 & 0.3757 & 0.3702 & 0.3631 \\
\hline 100 & 1 & 0.0439 & 0.0459 & 0.0468 & 0.0470 & 0.0838 & 0.0711 & 0.0669 & 0.0631 \\
\hline
\end{tabular}


SOUTH. BRAZ. J. CHEM., Vol. 21, No.21, 2013

Thermodynamics of Solvation of Barium Diphenylaminesulfonate

38

Table 2. Solubility products and Gibbs free energies of solvation for barium diphenylaminesulfonate in mixed $\mathrm{E} t \mathrm{OH}-\mathrm{H}_{2} \mathrm{O}$ solvents at different temperature.

\begin{tabular}{|c|c|c|c|c|c|c|c|c|}
\hline $\begin{array}{c}X_{s,} \\
E_{10 H}\end{array}$ & \multicolumn{5}{|c|}{$p_{\text {sp }}$} & \multicolumn{5}{c|}{$\Delta \mathrm{G}_{\mathrm{s},}, \mathrm{JJ} / \mathrm{mol}$} \\
\hline & $293.15 \mathrm{~K}$ & $298.15 \mathrm{~K}$ & $303.15 \mathrm{~K}$ & $308.15 \mathrm{~K}$ & $293.15 \mathrm{~K}$ & $298.15 \mathrm{~K}$ & $303.15 \mathrm{~K}$ & $308.15 \mathrm{~K}$ \\
\hline 0 & 2.0246 & 1.9543 & 1.8855 & 1.8553 & 11.364 & 11.157 & 10.944 & 10.947 \\
\hline 0.0717 & 4.0974 & 4.0661 & 3.9608 & 3.9081 & 22.999 & 23.212 & 22.99 & 23.059 \\
\hline 0.1708 & 4.1848 & 4.1526 & 4.1410 & 4.1519 & 23.489 & 23.706 & 24.037 & 24.497 \\
\hline 0.3166 & 4.3591 & 4.3152 & 4.3102 & 4.2963 & 24.468 & 24.634 & 25.019 & 25.349 \\
\hline 0.5527 & 4.6841 & 4.6745 & 4.6807 & 4.6891 & 26.292 & 26.686 & 27.169 & 27.667 \\
\hline 1 & 6.7008 & 6.8562 & 6.9206 & 6.9812 & 37.612 & 39.141 & 40.171 & 41.191 \\
\hline
\end{tabular}

Table 3. Transfer Gibbs free energies, enthalpy and entropy of solvation for barium diphenylaminesulfonate in mixed $\mathrm{EtOH}-\mathrm{H}_{2} \mathrm{O}$ solvents at different temperature.

\begin{tabular}{|c|c|c|c|c|c|c|c|c|c|}
\hline \multirow{2}{*}{$\begin{array}{c}\mathrm{X}_{\mathrm{s},} \\
\mathrm{EtOH}\end{array}$} & \multicolumn{4}{|c|}{$\Delta \mathrm{G}_{\mathrm{t}} \mathrm{kJ} / \mathrm{mol}$} & \multicolumn{3}{c|}{$\Delta \mathrm{H}_{\mathrm{s},}$} \\
\cline { 4 - 10 } & $293.15 \mathrm{~K}$ & $298.15 \mathrm{~K}$ & $303.15 \mathrm{~K}$ & $308.15 \mathrm{~K}$ & $\mathrm{~kJ} / \mathrm{mol}$ & $293.15 \mathrm{~K}$ & $298.15 \mathrm{~K}$ & $303.15 \mathrm{~K}$ & $308.15 \mathrm{~K}$ \\
\hline 0 & 0.000 & 0.000 & 0.000 & 0.000 & 20.006 & 8.642 & 8.850 & 9.062 & 9.060 \\
\hline 0.0717 & 11.634 & 12.055 & 12.046 & 12.112 & 23.206 & 0.188 & 0.205 & 0.216 & 0.224 \\
\hline 0.1708 & 12.125 & 12.549 & 13.092 & 13.550 & 3.889 & -19.601 & -19.818 & -20.148 & -20.609 \\
\hline 0.3166 & 13.104 & 13.478 & 14.074 & 14.402 & 6.714 & -17.754 & -17.920 & -18.305 & -18.635 \\
\hline 0.5527 & 14.928 & 15.529 & 16.225 & 16.720 & -0.717 & -27.009 & -27.403 & -27.886 & -28.384 \\
\hline 1 & 26.247 & 27.984 & 29.226 & 30.244 & -31.432 & -69.043 & -70.572 & -71.602 & -72.622 \\
\hline
\end{tabular}

VISIT OUR STE: http:/Www.sbjchem.he.com.br 


\section{CONCLUSIONS}

The solubility of saturated solution of barium diphenylaminesulfonate in mixed solvents found to decrease with the increase the mole fraction of EtOH in the mixed solvent and increase with increasing the temperature. In addition, Gibbs energy, enthalpy, entropy for the solution processes and free energies of transfer were also calculated in order to estimate the contributions solute-solvent interactions related ion association are based on changes in the electrostatic properties of the solvent, solute and ion solvation as well as on the ionic strength of the medium. The saturated solution of diphenyl amine barium salt in the mixed solvent is perfectly non-ideal. The non-ideality is partly due to the mean activity coefficient of ions in the solution and partly due to the ion association phenomenon. By choosing a suitable model for estimating the mean activity coefficient and using the iteration calculations, we obtained the value of ion-pair concentration and the activity coefficient contribution and ion association contribution to the solubility of the considered ionic compound in the considered mixed solvent at different temperature.

\section{ACKNOWLEDGEMENTS}

This work was supported by Chemistry Department, Faculty of Science, Mansoura University and Basic Science Department, Delta Higher Institute for Engineering and Technology, Dakhlia, Mansoura, Egypt.

\section{REFERENCES}

[1] Marcus, Y., Pure Appl. Chem., 1990, 62, 2069-2076.

[2] Water and aqueous solutions, in: R.A. Home (Ed). 1972.

[3] M. Aghaie; H. Aghaie, J. Mol. Liq., 135, (2007), 72.

[4] M. Aghaie, S. Ghafoorain, B.Sh. Broojeni, H. Aghaie, J. Phys. Theor Chem, 5, $(2009), 223$.

[5] Y. Marcus. Ion Solvation, John Wiley, New York (1985).

[6] G. A. Krestov, N. P. Novosyolov, I. S. Perelygin, A. M. Kolker, L. P. Safonova, V. D. Ovchinnikova, V. N. Trostin. Ionic Solvation, Ellis Horwood, Chichester, UK (1994).

[7] O. Popovych and R. P. T. Tomkins. Nonaqueous Solution Chemistry, John Wiley, New York (1981).

[8] M. Aghaie, B. Sh. Broojeni. J. Phys. Theor. Chem, 3, (2007), 249.

[9] M. Aghaie, E, Samaie, J. Mol. Liq. 126, (2006), 305.

[10] N. Bjerrum, K. Danske vidensk. Selsk (Match. Fys. Medd), 7, (1926), 9

[11] Ion Assiciation, by Davies, C. W, 1962.

[12] R.W.Margaret. L. J. P.Lain. D. M. H. Kenneth, J. Chem. Ed. 75/3 (1998) 352. 


\section{SOUTHERN BRAZILIAN, JOURNAL OF CHEMISTRY}

SOUTH. BRAZ. J. CHEM. , Vol. 21, No. 21, 2013

Thermodynamics of Solvation of Barium Diphenylaminesulfonate

40

[13] H. Aghaie, M. Aghaie, A. Ebrahimi, J. Phys. Theor. Chem, 2, (2005), 151.

[14] M. Aghaie, S. Gafoorian, J. Chem. Eng. Data, 55 (2010) 1867.

[15] P. Debye, E. Huckel, Z. Phys. 24 (1923)185, 305.

[16] M. Aghaie, B. S. Broojeni, J. Phys. Theor. Chem, 3 (2007) 249.

[17] M. Aghaie, E. Samaie, J. Mol. Liq, 126 (2006) 72.

[18] M. Aghaie, F. Ghaemi. A, M. Giahi, J. Phys. Theor. Chem, 2 (2005) 33.

[19] H. Aghaie, A. AliABA2di, B. Sohrabi, M. Aghaie, M. R. Sohrabi, J. Phys. Theor. Chem, 1 (2004) 143.

[20] M. R. Wright, I.L.L. Patterson, K.D. M. Harris, J. Chem. Educ, 75930

(1998) 352.

[21] E. C. Zhong, H. L. Friedman, J. Phys. Chem, 92 (1988) 1685.

[22] El-khouly, A. A., Gomaa, E. A., and Abou El-leef, S., (Bulletin of electrochemistry 19(5) May 2003, pp193-202).

[23] N. Bjerrum, Mat. Fys. Medd. K. Dan. Vidensk. Selsk, 7 (1926) 1.

[24] M. Aghaie, S. Gafoorian, B. S. Broojeni, H. Aghaie, J. Phys. Theor. Chem, 5 (2009) 223.

[25] M. Aghaie, H. Aghaie, A. Ebrahimi, J. Mol. Liq. 135 (2007) 72.

[26] D. E. Smith, Y. V. Kalyuzhnyi, A. D. J. Haymet, J. Chem. Phys, 95 (1991) 9165.

[27] Davies, C.W. Ion Association. London: Butterworths. (1962) p. 37-53.

[28] Gomaa, E. A., Eur. Chem. Bull., 2013, 1(5) 254-261.

[29] Gomaa, E. A., and Al-Jahdali, Science and Technology, 2012, 2(4) 66-76.

[30] Gomaa, E. A., Global Ad. Rescarch J. of Chem. and Material Science, 1(2), 35-38, 2012.

[31] Gomaa, E. A., AbuEl-Nader, H. M. and Rashed, Sh. E., Physical Chemistry, 2012, 2(3) 9-17.

[32] Dickerson R.E. and Geis I,Chemistry, Matter and the Universe, W.A. Benjamin, Menlo Park, CA., 1976.

[33] Chemical Thermodynamics, D.J.G. Ives, University Chemistry, Macdonald Technical and Scientific, 1971.

VISIT OUR SITE: http://www.sbjchern.he.com.br 